\title{
Prevalens dan Profil Klinis pada Anak Palsi Serebral Spastik dengan Epilepsi
}

\author{
Alinda Rubiati Wibowo, Deddy Ria Saputra \\ Departemen Ilmu Kesehatan Anak RSUP Fatmawati, Jakarta
}

Latar belakang. Epilepsi setiap kali ditemukan pada anak palsi serebral (15\%-90\%), khususnya pada palsi serebral spastik. Pengobatan epilepsi pada palsi serebral biasanya lebih sulit dan membutuhkan waktu lebih lama. Berbagai profil klinis pada anak palsi serebral, di antaranya adalah berat lahir rendah, kejang neonatal, kejang pertama pada usia $\leq 1$ tahun, riwayat epilepsi pada keluarga, retardasi mental, dan kelainan CT scan/MRI kepala.

Tujuan. Mengetahui prevalens dan profil klinis pada anak palsi serebral spastik dengan epilepsi.

Metode. Penelitian deskriptif potong lintang menggunakan data sekunder pasien palsi serebral spastik di SMF Kesehatan Anak RSUP Fatmawati sejak 1 Januari 2008 sampai 31 Desember 2010.

Hasil. Didasarkan 191 pasien palsi serebral spastik diikutsertakan dalam penelitian. Rasio laki-laki dan perempuan 1:1.1. Prevalens epilepsi pada palsi serebral spastik 50,8\%. Profil klinis pada anak palsi serebral spastik dengan epilepsi yang ditemukan adalah asfiksia, usia gestasi kurang bulan, proses persalinan dengan tindakan, berat lahir rendah, infeksi susunan saraf pusat, kejang neonatal, kejang pertama pada usia $\leq 1$ tahun, riwayat epilepsi dalam keluarga, CT scan kepala, dan kelainan EEG. Angka kejadian anak palsi serebral spastik dengan epilepsi yang belum bebas kejang yaitu 49,5\%.

Kesimpulan. Prevalens epilepsi pada anak palsi serebral spastik sebesar 50,8\%. Profil klinis ditemukan pada anak palsi serebral spastik dengan epilepsi di antaranya adalah asfiksia, usia gestasi kurang bulan, proses persalinan dengan tindakan, berat lahir rendah, infeksi susunan saraf pusat, kejang neonatal, kejang pertama pada usia $\leq 1$ tahun, riwayat epilepsi dalam keluarga, kelainan lingkar kepala, kelainan CT scan kepala, dan kelainan EEG. Angka kejadian anak palsi serebral spastik dengan epilepsi yang belum bebas kejang 49,5\%. Sari Pediatri 2012;14(1):1-7.

Kata kunci: palsi serebral, epilepsi

P alsi serebral merupakan suatu keadaan kerusakan jaringan otak yang menetap dan tidak progresif, terjadi pada usia dini sehingga mengganggu perkembangan otak

\section{Alamat korespondensi:}

Dr. Alinda Rubianti Wibowo, Sp.A, Departemen Ilmu Kesehatan Anak RSUP Fatmawati Jakarta, Telp. (021) 7660588, Fax. (021) 7690123 dan menunjukkan kelainan posisi, tonus otot dan koordinasi motorik, serta kelainan neurologis lainnya. ${ }^{1,2}$ Angka kejadian palsi serebral di berbagai negara bervariasi antara $2-2,5$ per 1000 kelahiran hidup. ${ }^{3}$ Secara umum, palsi serebral dibagi atas 4 tipe yaitu spastik, atetoid, ataksia, dan campuran. ${ }^{4}$ Sekitar 70\%-80\% kasus palsi serebral adalah tipe spastik.,

Berbagai manifestasi neurologis dapat dijumpai 
pada pasien palsi serebral, salah satunya adalah epilepsi. Epilepsi merupakan gejala gangguan fungsi otak yang sering ditemukan, dan dapat menyebabkan kerusakan otak jika kejang berlangsung lebih dari 30 menit. Berbagai penelitian epidemiologi memperlihatkan bahwa defisit neurologis seperti palsi serebral, akan meningkatkan risiko terjadinya epilepsi, dan mekanisme terjadinya epilepsi pada palsi serebral sama dengan mekanisme pada populasi umum. ${ }^{7}$ Setiap kerusakan otak yang terjadi berpotensi untuk menyebabkan epilepsi. Beberapa penelitian mendapatkan bahwa sekitar sepertiga anak palsi serebral mengalami epilepsi. Epilepsi pada anak palsi serebral sulit dikontrol, dan dapat meningkatkan derajat berat gangguan motor dan fungsi kognitif, oleh karena itu prognosisnya buruk. ${ }^{8,9}$

Kejadian epilepsi pada anak palsi serebral berhubungan dengan profil klinis tertentu. Penelitian Kulak $\mathrm{dkk}^{8}$ melaporkan beberapa faktor risiko yang berperan untuk terjadinya epilepsi pada anak palsi serebral di antaranya berat lahir rendah, kejang neonatal, kejang pertama pada usia $\leq 1$ tahun, riwayat epilepsi pada keluarga, retardasi mental, dan kelainan pada pemeriksaan magnetic resonance imaging (MRI) kepala, computed tomography scan (CT scan) kepala.

Beberapa penelitian sering menghubungkan kejadian epilepsi pada palsi serebral tipe tertentu. ${ }^{10}$ Penelitian Paucic-Kirincic dkk ${ }^{11}$ melaporkan bahwa epilepsi paling sering ditemukan pada anak palsi serebral tipe spastik. Rahmat $\mathrm{dkk}^{12}$ melaporkan dalam penelitiannya bahwa 39\% anak palsi serebral spastik mengalami epilepsi. Palsi serebral spastik mengalami kerusakan otak yang lebih berat dan melibatkan korteks serebri, sehingga epilepsi lebih sering ditemukan pada tipe ini. ${ }^{8,9}$

Prevalens epilepsi pada anak palsi serebral mempunyai rentang yang sangat lebar yaitu 15\%$90 \%$, sehingga masih merupakan hal yang menarik untuk diteliti. ${ }^{8}$ Penelitian metaanalisis oleh Ashwal $\mathrm{dkk}^{13}$ mendapatkan prevalens epilepsi pada anak palsi serebral 36\%-62\%, sedangkan Sianturi $\mathrm{dkk}^{14}$ melaporkan prevalens epilepsi pada anak palsi serebral $37,3 \%$.

Berdasarkan uraian tersebut, maka dilakukan penelitian mengenai prevalens dan profil klinis pada anak palsi serebral spastik dengan epilepsi di Rumah Sakit Umum Pusat Fatmawati (RSF). Penelitian ini bertujuan untuk mengetahui prevalens dan berbagai profil klinis pada anak palsi serebral spastik dengan epilepsi di RSF.

\section{Metode}

Penelitian merupakan penelitian deskriptif potonglintang untuk mengetahui prevalens dan profil klinis pada anak palsi serebral spastik dengan epilepsi. Penelitian dilakukan di Poliklinik Rawat Jalan SMF Kesehatan Anak RSF Jakarta, pada Februari 2011. Subjek penelitian adalah semua pasien anak palsi serebral spastik yang terdaftar di Poliklinik Rawat Jalan Neurologi SMF Kesehatan Anak RSF dalam kurun waktu 1 Januari 2008 - 31 Desember 2010. Kriteria eksklusi adalah pasien yang mengalami kelainan metabolik bawaan, sindrom genetik, gejala gangguan motorik, postur, dan tonus setelah usia 3 tahun.

Pengumpulan data dilakukan dengan cara penelusuran rekam medis pasien palsi serebral spastik yang berobat ke Poliklinik Rawat Jalan Neurologi SMF Kesehatan Anak RSF dalam kurun waktu 1 Januari 2008 - 31 Desember 2010. Seluruh rekam medis pasien yang memenuhi kriteria inklusi dimasukkan dalam penelitian.

Variabel yang diteliti adalah asfiksia, usai gestasi kurang bulan, proses kelahiran, berat lahir rendah, infeksi susunan saraf pusat (SSP), kejang neonatal, kejang pertama pada usia $\leq 1$ tahun, riwayat epilepsi dalam keluarga, kelainan lingkar kepala, abnormalitas gambaran EEG, dan CT scan kepala.

Seluruh data dicatat pada formulir khusus, dan diolah menggunakan program SPSS versi 17 untuk Windows. Data karakteristik numerik dinyatakan dalam bentuk rerata, standar deviasi bila distribusi normal, sedangkan data kategorikal dinyatakan sebagai prevalens (jumlah) dan persentase. Hasil pengolahan data disajikan dalam bentuk tekstular atau tabular.

\section{Hasil}

Berdasarkan penelusuran rekam medis di Poliklinik Rawat Jalan Neurologi SMF Kesehatan Anak RSF dalam kurun waktu 1 Januari 2008 sampai 31 Desember 2010, didapatkan 191 pasien palsi serebral spastik dan seluruh pasien memenuhi kriteria inklusi penelitian. Rerata usia saat diagnosis palsi serebral spastik ditegakkan 27,8 bulan dengan rentang usia 7-60 bulan.

Didapatkan subjek laki-laki dan perempuan dengan perbandingan 1:1,1. Berdasarkan riwayat kelahiran didapatkan kelahiran spontan pada 160 subjek $(83,8 \%)$, 
usia gestasi cukup bulan pada 151 subjek $(79,1 \%)$ dan berat lahir normal didapatkan pada 147 subjek (77\%) (Tabel 1). Manifestasi klinis pasien palsi serebral spastik berupa kelainan lingkar kepala 168 subjek (88\%) dan komorbiditas epilepsi 97 subjek (50,8\%).

Tabel 1. Karakteristik subjek

\begin{tabular}{lcc}
\hline Karakteristik & Jumlah $(\mathrm{n}=191)$ & $\%$ \\
\hline Jenis kelamin & & \\
$\quad$ Laki-laki & 91 & 47,6 \\
$\quad$ Perempuan & 100 & 52,4 \\
Proses kelahiran dengan tindakan & 31 & 16,2 \\
Usia gestasi kurang bulan & 40 & 20,9 \\
Berat lahir rendah & 44 & 23 \\
Kelainan lingkar kepala & 168 & 88 \\
Epilepsi & 97 & 50,8 \\
\hline
\end{tabular}

lebih dari satu tahun dan 48 subjek (49,5\%) masih mengalami kejang setelah diterapi OAE (Tabel 3). Obat anti epilepsi yang paling banyak digunakan untuk terapi epilepsi pada anak palsi serebral spastik adalah asam valproat diberikan pada 68 subjek $(70,1 \%)$.

Tabel 3. Terapi dan durasi bebas kejang

\begin{tabular}{lccc}
\hline \multirow{2}{*}{ Parameter } & \multicolumn{2}{c}{ Tipe epilepsi } & \multirow{2}{*}{ Total (\%) } \\
\cline { 2 - 3 } & Parsial & Umum & \\
\hline Cara pengobatan & & & \\
Monoterapi & 14 & 59 & $73(75,3)$ \\
$\quad \begin{array}{c}\text { Politerapi } \\
\text { Durasi bebas kejang (tahun) }\end{array}$ & 4 & 20 & $24(24,7)$ \\
$\leq 1$ & 4 & 25 & $29(29,9)$ \\
$>1$ & 3 & 17 & $20(20,6)$ \\
$\quad$ Masih kejang & 11 & 37 & $48(49,5)$ \\
\hline
\end{tabular}

Tabel 2. Profil klinis anak palsi serebral spastik

\begin{tabular}{lcc}
\hline \multirow{2}{*}{ Profil klinis } & \multicolumn{2}{c}{ Palsi serebral } \\
\cline { 2 - 3 } & Epilepsi $(+)$ & Epilepsi $(-)$ \\
\hline Asfiksia $(\%),(\mathrm{n}=191)$ & $35(36,1)$ & $42(44,7)$ \\
Usia gestasi kurang bulan (\%), (n=191) & $21(21,6)$ & $19(20,2)$ \\
Proses persalinan dengan tindakan (\%), (n=191) & $16(16,5)$ & $15(16)$ \\
Berat lahir rendah (\%), $(\mathrm{n}=191)$ & $22(22,7)$ & $22(23,4)$ \\
Infeksi susunan saraf pusat (\%), (n=157) & $59(75,6)$ & $54(68,4)$ \\
Kejang neonatal (\%), (n=191) & $0(0)$ & $7(7,4)$ \\
Kejang pertama pada usia $\leq 1$ tahun (\%), (n=191) & $39(40,2)$ & $38(40,4)$ \\
Epilepsi dalam keluarga $(\%),(\mathrm{n}=186)$ & $3(3,2)$ & $0(0)$ \\
Kelainan lingkar kepala $(\%),(\mathrm{n}=191)$ & $83(85,6)$ & $85(90,4)$ \\
Kelainan CT scan $(\%),(\mathrm{n}=80)$ & $32(88,9)$ & $44(100)$ \\
Kelainan EEG $(\%),(\mathrm{n}=80)$ & $61(88,4)$ & $10(90,9)$ \\
\hline
\end{tabular}

Ditemukan berbagai profil klinis anak palsi serebral spastik, di antaranya adalah asfiksia, usia gestasi kurang bulan, proses persalinan dengan tindakan, berat lahir rendah, infeksi susunan saraf pusat, kejang neonatal, kejang pertama pada usia $\leq 1$ tahun, riwayat epilepsi dalam keluarga, kelainan lingkar kepala, kelainan CT scan kepala, dan kelainan EEG (Tabel 2).

Tipe epilepsi yang paling sering ditemukan pada anak palsi serebral spastik adalah epilepsi umum 79 subjek $(81,4 \%)$, dan epilepsi parsial 18 subjek (18,6\%). Pengobatan epilepsi pada anak palsi serebral spastik dengan pemberian obat anti epilepsi (OAE) monoterapi didapatkan 73 subjek $(75,3 \%)$. Dua puluh subjek $(20,6 \%)$ palsi serebral spastik dengan epilepsi pada penelitian kami mengalami bebas kejang

\section{Pembahasan}

Penelitian kami merupakan deskriptif potonglintang dengan menggunakan data sekunder rekam medis pasien ke Poliklinik Rawat Jalan Neurologi SMF Kesehatan Anak RSF. Pencatatan data pasien kurang sistematis dan lengkap, sehingga mempersulit pengumpulan data dari rekam medis.

Keterangan profil klinis pasien palsi serebral spastik tidak selalu ditemukan dalam seluruh rekam medis. Kelengkapan data rekam medis ini yang mencakup infeksi susunan saraf pusat $82,2 \%$, epilepsi dalam keluarga 97,4\%, kelainan CT scan kepala 41,9\%, dan kelainan EEG 41,9\%. Deskripsi kelainan CT scan kepala ini kurang spesifik, karena 
hanya menyatakan kesan normal atau abnormal tanpa adanya deskripsi lengkap dari pemeriksaan yang mendukung kemungkinan adanya gambaran lesi spesifik untuk epilepsi. Demikian juga deskripsi kelainan EEG yang spesifik untuk epilepsi tidak selalu didapatkan karena pemeriksaan dilakukan dalam waktu $<24$ jam.

Usia gestasi kurang bulan, berat lahir rendah dan proses kelahiran dengan tindakan tidak banyak ditemukan. Pada temuan kami, terdapat 20,9\% kasus usia gestasi kurang bulan, 23\% berat lahir rendah, dan $16,2 \%$ proses kelahiran dengan tindakan. Keadaan tersebut menunjukkan bahwa ketiga profil klinis yang sering dianggap sebagai penyebab palsi serebral ternyata tidak banyak ditemukan, hal tersebut menunjukkan kemungkinan penyebab palsi serebral spastik terjadi pada masa pascanatal.

Kelainan lingkar kepala merupakan manifestasi klinis pasien palsi serebral spastik yang paling banyak ditemukan (88\%). Angka kejadian kelainan lingkar kepala ini berbanding terbalik dengan angka kejadian usia gestasi kurang bulan dan berat lahir rendah. Hal tersebut menunjukkan bahwa kelainan lingkar kepala pada palsi serebral spastik mungkin terjadi pada masa pascanatal, yang disebabkan oleh gangguan pada saat perkembangan otak belum selesai yaitu pada usia kurang dari 3 tahun. Penyebab kelainan lingkar kepala paling mungkin adalah infeksi SSP (72\%). Infeksi SSP dapat menyebabkan kelainan lingkar kepala dengan cara penghancuran masa otak sehingga menyebabkan mikrosefalus atau terjadi penyumbatan aliran cairan serebrospinal dalam sistem ventrikel sehingga menyebabkan hidrosefalus. ${ }^{15}$

Didapatkan 97 dari 191 subjek (50,8\%) palsi serebral spastik mengalami epilepsi. Hasil tersebut tidak jauh berbeda dengan penelitian Kulak dkk ${ }^{8}$ yang mendapatkan 76 dari 172 subjek (44,2\%) palsi serebral spastik mengalami epilepsi. Demikian juga dengan penelitian Rahmat dkk, ${ }^{12}$ yang mendapatkan 92 dari 236 subjek (39\%) palsi serebral spastik menderita epilepsi.

Penelitian Bruck dkk ${ }^{16}$ mendapatkan prevalens epilepsi pada anak palsi serebral spastik $62 \%$, lebih besar dibandingkan dengan penelitian kami. Hal tersebut mungkin berhubungan dengan sekitar 35\% subjek tidak kontrol teratur, sehingga banyak subjek yang belum muncul manifestasi klinis epilepsi sudah hilang dari pemantauan.
Manifestasi klinis epilepsi pada anak palsi serebral tergantung dari letak dan luas kerusakan otak. Tipe epilepsi yang sering ditemukan pada palsi serebral yaitu epilepsi dengan kejang tonik klonik dan kejang parsial. Kedua tipe epilepsi ini lebih sering terjadi pada palsi serebral spastik, oleh karena terdapat keterlibatan korteks dan derajat kerusakan otak. ${ }^{16,17}$

Tipe epilepsi pada anak palsi serebral spastik yang paling sering ditemukan adalah epilepsi umum $81,4 \%$ kasus. Penelitian Bruck dkk, ${ }^{16}$ Senbil dkk, ${ }^{18}$ Zafeiriou $\mathrm{dkk},{ }^{19}$ dan Singhi $\mathrm{dkk}^{20}$ juga mendapatkan epilepsi umum merupakan tipe epilepsi yang paling sering ditemukan pada anak palsi serebral yaitu masingmasing $45,2 \%, 61,3 \%$, 44,4\%, dan $38,1 \%$.

Setiap perubahan pada otak dapat menjadi faktor risiko terjadinya epilepsi. Beberapa faktor risiko tersebut di antaranya malformasi SSP, infeksi SSP, gangguan neurologis, kejang neonatal, kejang pertama pada usia $\leq 1$ tahun, riwayat epilepsi dalam keluarga, kelainan pada CT scan/MRI kepala dan EEG. ${ }^{7,21}$ Beberapa profil klinis anak palsi serebral spastik dengan epilepsi yang ditemukan pada adalah asfiksia, usia gestasi kurang bulan, proses persalinan dengan tindakan, berat lahir rendah, infeksi susunan saraf pusat, kejang neonatal, kejang pertama pada usia $\leq 1$ tahun, riwayat epilepsi dalam keluarga, kelainan lingkar kepala, kelainan CT scan kepala, dan kelainan EEG. Profil klinis yang didapatkan mungkin merupakan faktor risiko terjadinya epilepsi.

Infeksi SSP sering ditemukan di negara sedang berkembang, dan 30\%-50\% kasus di antaranya akan mengalami kecacatan. Kecacatan yang paling sering ditemukan adalah palsi serebral dan epilepsi, yang dapat terjadi bersamaan atau berdiri sendiri. Beberapa kepustakaan menyatakan bahwa risiko terjadinya epilepsi meningkat bila palsi serebral terjadi akibat komplikasi infeksi SSP. ${ }^{21,22}$

Proporsi subjek yang mengalami infeksi SSP pada kelompok palsi serebral spastik dengan epilepsi dalam adalah 75,6\%. Hasil tersebut menunjukkan angka kecacatan akibat infeksi SSP di Indonesia yang tinggi. Lagunju dkk ${ }^{21}$ melaporkan $73,7 \%$ pasien palsi serebral spastik dengan epilepsi.

Kejadian kejang pertama pada usia $\leq 1$ tahun sering dihubungkan dengan kejadian epilepsi di masa datang. Hal ini disebabkan pada rentang usia ini otak masih dalam proses perkembangan sehingga setiap gangguan yang terjadi mungkin akan menyebabkan kerusakan otak. Bila kejang berlangsung dalam waktu 
yang lama, akan meningkatkan risiko kerusakan otak. $^{8,21}$

Penelitian kami menemukan 40,2\%, kejang pertama pada usia $\leq 1$ tahun. Hasil tersebut lebih kecil bila dibandingkan dengan penelitian Rahmat $\mathrm{dkk}^{12}$ yang melaporkan bahwa $86 \%$ subjek palsi serebral spastik dengan epilepsi mengalami kejang pertama pada usia $\leq 1$ tahun. Penelitian Lagunju $\mathrm{dkk}^{21}$ melaporkan bahwa 77,4\% subjek palsi serebral spastik dengan epilepsi mengalami kejang pertama pada usia $\leq 1$ tahun.

Epilepsi merupakan kelainan klinis dan untuk menegakkan diagnosis tidak tergantung pada pemeriksaan EEG. Gangguan fungsi otak tidak selalu dapat tercermin pada rekaman EEG. Pemeriksaan EEG normal dapat ditemukan pada anak yang secara jelas menderita epilepsi, demikian juga EEG abnormal dapat ditemukan pada anak normal. ${ }^{23,24}$

Kulak dkk ${ }^{8}$ melaporkan bahwa dari seluruh subjek yang dilakukan pemeriksaan EEG didapatkan sebanyak 92,7\% subjek pada kelompok palsi serebral dengan epilepsi mempunyai kelainan EEG. Dalam penelitian kami, pemeriksaan EEG hanya dilakukan pada 80 dari 191 subjek palsi serebral spastik $(41,8 \%)$ dan 61 dari 69 subjek $(88,4 \%)$ pada kelompok palsi serebral spastik dengan epilepsi mengalami kelainan EEG. Di jumpai 88,4\% subjek pada kelompok palsi serebral spastik dengan epilepsi mengalami kelainan EEG, namun kelainan EEG yang ditemukan belum tentu spesifik untuk epilepsi. Hal tersebut terjadi karena pemeriksaan EEG dilakukan dalam waktu $<24$ jam, sehingga gambaran yang spesifik untuk epilepsi belum tentu muncul pada saat pemeriksaan dilakukan.

Kami juga mendapatkan beberapa profil klinis lain di antaranya asfiksia, usia gestasi kurang bulan, proses kelahiran dengan tindakan, berat lahir rendah, kejang neonatal, kelainan lingkar kepala,epilepsi dalam keluarga, dan kelainan CT scan kepala. Asfiksia merupakan suatu keadaan yang dapat menyebabkan otak dalam kondisi hipoksia, iskemia, dan hiperkapnia, sehingga dapat terjadi kerusakan otak. Kerusakan otak menyebabkan terjadinya palsi serebral di kemudian hari dan bila mengenai area tertentu seperti korteks serebri dan lobus temporal akan menyebabkan terjadinya epilepsi. ${ }^{25}$ Kami mendapatkan 36,1\% subjek mengalami asfiksia.

Kejadian berat lahir rendah tidak selalu berkaitan dengan usia gestasi kurang bulan. Sekitar 30\%-40\% bayi dengan berat lahir rendah dilahirkan cukup bulan dan dinyatakan sebagai kecil menurut usia gestasi, sehingga dianggap mengalami pertumbuhan janin terhambat. Pada keadaan ini terjadi deviasi antara lingkar kepala dan berat lahir bayi. Bayi dengan pertumbuhan janin terhambat lebih berisiko tinggi mengalami masalah neurologis dan morbiditas lainnya dibandingkan bayi tanpa pertumbuhan janin terhambat. ${ }^{26}$

Pada penelitian kami, proporsi usia gestasi kurang bulan, berat lahir rendah, dan proses kelahiran dengan tindakan berturut-turut $21,6 \%, 22,7 \%$, dan $16,5 \%$ pada kelompok palsi serebral spastik dengan epilepsi. Sebanding dengan hasil penelitian Rahmat dkk, ${ }^{12}$ yang mendapatkan usia gestasi kurang bulan 13\%, berat lahir rendah $15,2 \%$, dan proses kelahiran dengan tindakan $17,4 \%$ subjek.

Kejang neonatal meningkatkan risiko kematian dan terjadinya sekuele neurologis pada neonatus berupa epilepsi. Pada berbagai penelitian sebelumnya dilaporkan bahwa kejang neonatal merupakan faktor risiko yang berperan untuk terjadinya epilepsi pada pasien palsi serebral..$^{8,12,27}$ Penelitian Widiastuti $\mathrm{dkk}^{27}$ yang dilakukan pada 3 rumah sakit pendidikan di Jakarta mendapatkan angka mortalitas kejang neonatal 47,4\%. Mortalitas kejang neonatal berhubungan dengan derajat kondisi klinis neonatus setelah lahir. Penelitian ini tidak menemukan subjek yang mengalami kejang neonatal pada kelompok palsi serebral spastik dengan epilepsi. Hasil tersebut mungkin berhubungan dengan mortalitas yang tinggi pada kejang neonatal di Indonesia.

Riwayat epilepsi dalam keluarga meningkatkan risiko individual untuk mengalami epilepsi. Kondisi genetik yang diwariskan dari generasi ke generasi mungkin menyebabkan terjadinya epilepsi. Pada negara-negara dengan kejadian perkawinan kosanguinitas tinggi seperti di Yordania, Turki, dan Pakistan menyebabkan transmisi genetik epilepsi lebih tinggi dari pada di tempat lain. Riwayat epilepsi dalam keluarga pada pasien dengan palsi serebral akan semakin meningkatkan risiko terjadi epilepsi. ${ }^{28}$ Penelitian kami hanya mendapatkan 3,2\% subjek dengan riwayat epilepsi dalam keluarga pada kelompok palsi serebral spastik dengan epilepsi. Hasil tersebut mungkin terjadi karena bias informasi mengenai riwayat epilepsi dalam keluarga, dan pada saat anamnesis orangtua belum tentu tahu tentang epilepsi. Keadaan ini dipengaruhi oleh tingkat pendidikan orangtua pasien. 
Kelainan lingkar kepala terjadi karena malformasi SSP yang dapat diketahui secara spesifik dari pemeriksaan CT scan ataupun MRI kepala. ${ }^{18}$ Ditemukan 85,6\% kelainan lingkar kepala pada kelompok palsi serebral spastik dengan epilepsi. Kelainan lingkar kepala mungkin saja berhubungan dengan kejadian epilepsi, namun dibutuhkan konfirmasi pemeriksaan CT scan ataupun MRI kepala untuk memastikan kelainan otak yang spesifik.

Pemeriksaan CT scan kepala hanya dilakukan pada 80 dari 191 subjek $(41,8 \%)$ dan 95\% diantaranya menunjukkan kelainan. Kelainan CT scan/MRI kepala pada kelompok palsi serebral spastik dengan epilepsi didapatkan pada 32 dari 36 subjek $(88,9 \%)$, namun tidak didapatkan deskripsi yang spesifik untuk epilepsi pada data rekam medis karena hanya dinyatakan hasil normal atau abnormal saja.

Pengobatan epilepsi pada anak palsi serebral dengan pemberian OAE jangka panjang secara monoterapi dan politerapi, sehingga dibutuhkan evaluasi respons pengobatan berkala. Respons pengobatan OAE pada epilepsi dianggap berhasil apabila pasien bebas kejang lebih dari satu tahun. ${ }^{29}$ Pada penelitian kami sebagian besar subjek diberikan pengobatan OAE secara monoterapi $75,3 \%$ subjek. Sebanding dengan penelitian Bruck dkk ${ }^{16}$ bahwa sebagian besar pasien epilepsi pada palsi serebral diberikan OAE monoterapi.

Perjalanan penyakit dan respons pengobatan kejang epilepsi berhubungan dengan derajat berat palsi serebral. Epilepsi pada anak palsi serebral pada umumnya sulit dikontrol jika terdapat kerusakan otak yang luas atau berhubungan dengan sindrom epilepsi. ${ }^{30,31}$ Pengobatan epilepsi pada anak palsi serebral lebih sulit dihentikan dan membutuhkan waktu lebih lama untuk mencapai bebas kejang selama 1-2 tahun dibandingkan anak epilepsi tanpa palsi serebral. Penghentian OAE dapat dan harus dilakukan jika pasien telah bebas kejang selama 2 tahun. ${ }^{29,32}$ Kami menemukan 48 (49,5\%) subjek palsi serebral spastik dengan epilepsi masih mengalami kejang setelah diterapi OAE.

Terdapat $20(20,6 \%)$ subjek mengalami bebas kejang lebih dari satu tahun dengan pemberian OAE. Hasil ini lebih sedikit dibandingkan penelitian Carlsson $\mathrm{dkk}^{33}$ dan Kwong $\mathrm{dkk}^{34}$ yang melaporkan bahwa 38\%-67\% anak palsi serebral dengan epilepsi mengalami bebas kejang lebih dari satu tahun.

Kesimpulan dari penelitian kami adalah prevalens epilepsi pada anak palsi serebral spastik 50,8\%. Berba- gai profil klinis pada anak palsi serebral spastik dengan epilepsi adalah asfiksia, usia gestasi kurang bulan, proses persalinan dengan tindakan, berat lahir rendah, infeksi susunan saraf pusat, kejang neonatal, kejang pertama pada usia $\leq 1$ tahun, riwayat epilepsi dalam keluarga, kelainan lingkar kepala, kelainan CT scan kepala, dan kelainan EEG. Terdapat 49,5\% kejadian anak palsi serebral dengan epilepsi yang belum bebas kejang.

Berdasarkan hasil tersebut disarankan untuk penelitian lebih lanjut dengan desain kohort dan multisenter menilai berbagai faktor risiko terjadinya epilepsi pada anak palsi serebral spastik dan respons terapi OAE yang diberikan. Penelitian ulang juga perlu dilakukan untuk pemeriksaan CT scan ataupun MRI kepala dan EEG dengan menggunakan deskripsi yang lebih spesifik supaya dapat lebih baik memperkirakan kemungkinan terjadinya epilepsi pada anak palsi serebral.

\section{Daftar pustaka}

1. Palmer FB. Strategy for early diagnosis of cerebral palsy. J Pediatr 2004;145(suppl):8-11.

2. Johnston MV. Encephalopathies. Dalam: Berhman RE, Kliegman RM, Arvin AM, penyunting. Nelson's textbook of pediatrics. Edisi ke-18. Saunder: Philadelphia; 2008. h. 2494-5.

3. Lin JP. The cerebral palsies: a physiology approach. J Neurol Neurosurg Psychiatry 2003;74(suppl):i2329.

4. Green L, Greenberg GM, Hurwitz E. Primary care of children with cerebral palsy. Clin Fam Pract 2003;5:46791.

5. Warner WC. Cerebral palsy. Dalam: Canale Campbell's operative orthopaedics. Edisi ke-10. Mosby: St Louis; 2003. h. 1214-21.

6. Koman LA, Smith BP, Shilt JS. Cerebral palsy. The Lancet 2004;363:1619-31.

7. Sankar R, Koh S, Wu J, Menkes JH. Paroxysmal disorders. Dalam: Menkes JH, Sarnat HB, Maria BL, penyunting. Child Neurology. Edisi ke-7. Lippincott Williams \& Wilkins: Philadelphia; 2006. h. 858-943.

8. Kulak W, Sobaniec W. Risk factor and prognosis of epilepsy in children with cerebral palsy in north-eastern Poland. Brain Dev. 2003;25:499-506.

9. Benassi G, Guarino M, Cammarata S. An epidemiological study on severe mental retardation among school children in Bologna, Italy. Dev Med Child Neurol 1990;32:895- 
901.

10. Arts WFH, Visser LH, Loonen MCB, Tjiam AT, Stroink H, Stuurmanm PM. Follow-up of 146 children with epilepsy after withdrawal of antiepileptic therapy. Epilepsia 1988;29:244-50.

11. Paucic-Kirincic E, Modrusan-Mozetic Z, SindicicSimundic N, Prpic I, Nekic M. Epilepsy among children with cerebral palsy born in Rijeka between 1982 and 1992. Medicina 2005;41:31-6.

12. Rahmat D, Mangunatmadja I, Tridjaja B, Tambunan T, Suradi R. Prevalence and risk factor for epilepsy in children with spastic cerebral palsy. Paediatr Indones 2010;50:11-7.

13. Ashwal S, Russman BS, Blasco PA, Miller G, Sandler A, Shevell M, Stevenson R. Practice parameter: diagnostic assessment of the child with cerebral palsy. Report of the quality standards subcommittee of the American Academy of Neurology and the practice committee of the child neurology society. Neurology 2004;62:85163.

14. Sianturi P, Syarifuddin A, Saing B. Incidence of epilepsy among patients with cerebral palsy. Pediatr Indones 2001;41:202-7.

15. Golden JA, Bonnemann CG. Developmental structural disorders. Dalam: Goezt CG penyunting. Goezt: Textbook of clinical neurology. Edisi ke-3. Saunders: Philadelphia; 2007. h. 568-85.

16. Bruck I, Antoniuk SA, Spessato A, de Bem RS, Hausberger R, Pacheco CG. Epilepsy in children with cerebral palsy. Arq Neuropsiquiatr 2001;59:35-9.

17. Singhi P, Jagirdar S, Khandelwal N, Malhi P. Epilepsy in children with cerebral palsy. J Child Neurol 2003;18:174-9.

18. Senbil N, Sonel B, Aydin OF, Gurer YK. Epileptic and non-epileptic cerebral palsy: EEG and cranial imaging findings. Brain Dev 2002;24:166-9.

19. Zafeiriou DI, Kontopoulos EE, Tsikoulas I. Characteristics and prognosis of epilepsy in children with cerebral palsy. J Child Neurol. 1999;14:289-94.

20. Singhi P, Jagirdar S, Khandelwal N, Malhi P. Epilepsy in children with cerebral palsy. J Child Neurol 2003;18:174-9.

21. Lagunju IOA, Adedokun BO, Fatunde OJ. Risk factor for epilepsy in children with cerebral palsy. AJNS 2006;25:29-37.

22. Gupta R, Appleton RE. Cerebral palsy: not always what it seems. Arch Dis Child 2001;85:356-60

23. Soetomenggolo TS. Pemeriksaan penunjang pada epilepsi. Dalam: Soetomenggolo TS, Ismael S; penyunting. Buku Ajar Neurologi Anak. Ikatan Dokter Anak Indonesia: Jakarta; 1999. h. 223-6.

24. Arzimanoglou A, Guerrini R, Aicardi J. Diagnosis and differential diagnosis. Dalam: Arzimanoglou A, Guerrini $\mathrm{R}$, Aicardi J, penyunting. Aicardi's epilepsy in children. Edisi ke-3. Saunders: Philadelphia. 2004. h. 325-41.

25. Freeman JM, Nelson KB. Intrapartum asphyxia and cerebral palsy. Pediatrics 1988;82:240-9.

26. Kliegman RM. Intrauterine growth restriction. Dalam: Martin RJ, Fanaroff AA, Walsh MC, penyunting. Fanaroff \& Martin's Neonatal-perinatal medicine. Edisi ke-8. Mosby: Philadelphia; 2006. h.271-303.

27. Widiastuti D, Mangunatmadja I, Tambunan T, Suradi R. Neonatal seizures: clinical manifestation and etiology. Pediatr Indones 2006;46:266-70.

28. Cansu A, Serdaroğlu A, Yüksel D, Doğan V, Özkan S, Hırfanoğlu T et al. Prevalence of some risk factors in children with epilepsy compared to their control. Seizure 2007;16:338-44.

29. Delgado MR, Riela AR, Mills J, Pitt A,Browne R. Discontinuation of antiepileptic drug treatment after two seizure-free years in children with cerebral palsy. Pediatrics 1996;97:192-7.

30. Carlsson M, Hargberg G, Olsson I. Clinical and aetiological aspects of epilepsy in children with cerebral palsy. Dev Med Child Neurol 2003;45:371-6.

31. Aicardi J. Epilepsy in brain-injured children. Dev Med Child Neurol 1990;32:191-202.

32. Camfield CS, Camfield PR, Watson L.Epilepsy in children with cerebral palsy. Diunduh dari: http://professionals.epilepsy.com. Diakses pada tanggal 6 Desember 2008.

33. Carlsson M, Hargberg G, Olsson I. Clinical and aetiological aspects of epilepsy in children with cerebral palsy. Dev Med Child Neurol 2003;45:371-6.

34. Kwong KL, Wong SN, So KT. Epilepsy in children with cerebral palsy. Pediatr Neurol 1998;19:31-6. 